\title{
Synthesis, Characterization, and Degradation Behaviors of End-Group-F unctionalized Poly(trimethylene carbonate)s
}

\author{
Faquan $\mathrm{YU}^{*, * * \dagger}$ and Renxi ZHUO** \\ *Department of Chemical Engineering, Hubei Key Laboratory of Novel Reactor and Green Chemical Technology, \\ Wuhan Institute of Chemical Technology, Wuhan, 430074 Hubei, China \\ ** Department of Chemistry, Wuhan University, Wuhan, 430072 Hubei, China
}

(Received February 18, 2003; Accepted April 25, 2003)

KEY WORDS Polycarbonate / Biodegradable Material / End-Group Effect /

Biodegradable polymers are under investigation for biomedical, pharmaceutical applications, etc. Degradability is one of their important characters. Many factors affect the degradation rate. Besides environmental conditions, such as temperature, the degradation rate is strongly dependent on the film thickness, ${ }^{1}$ additives such as monomer, ${ }^{2}$ basic compounds, ${ }^{3}$ acid drugs ${ }^{4}$ or superoxide ion, ${ }^{5}$ and catalyst such as SnOct $_{2}$ or zinc metal, ${ }^{6-9}$ etc. The molecular architecture, ${ }^{10-13}$ hydrophilicity, ${ }^{14-16}$ reasonable crosslink, ${ }^{17,}{ }^{18}$ and surface modification ${ }^{19,20}$ have vital influence on the degradation properties, too.

End-group effect is demonstrable on the degradation rate. ${ }^{21}$ It was shown that poly(lactide-co-glicolide) (PLGA) with a free carboxyl group at the polymer terminus (uncapped PLGA) degrades faster than PLGA with a hydrophobic alkyl ester linkage at the polymer terminus (capped PLGA). ${ }^{22}$ Lee $^{21}$ synthesized various end-group-functionalized, such as $\mathrm{OH}-, \mathrm{NH}_{2}-, \mathrm{Cl}-$, or $\mathrm{COOH}-$ terminated polylactides (PLAs) and found that the $\mathrm{COOH}$ end group plays a crucial role in the hydrolysis degradation in both alkaline and acidic medium. Protection of $\mathrm{OH}$ end group results in a substantial retarded degradation. ${ }^{23}$ Polyanhydrides capped with fatty terminals also show a significantly slow degradation and drug release rate. ${ }^{24}$

Linear aliphatic polycarbonates, such as poly(1,3trimethylene carbonate) (PTMC), have been shown to be potential for use as medical implants and for drugdelivery applications. ${ }^{25}$ But they degrade unexpectedly slow. ${ }^{10}$ Many efforts have been made to enhance their degradation rate. Copolymers of PTMC were synthesized for adapting to applications requiring different degradation rates and mechanical properties..$^{10,26-29}$ Pendant hydroxyl groups have been introduced to im- prove the hydrophilicity and hence the degradability. ${ }^{30}$

Since end groups have special effect on degradation rate, end-group functionalized polycarbonates will have different degradation rate. Because the polymers of multiarm architecture have a higher end-group concentration than linear polymers of the same molecular weights, the multiarm structure can strengthen the end group effect. Some researchers have synthesized the $\mathrm{OH}$-terminated PTMC by ring-opening polymerization (ROP), but the degradability has not been involved up to now. ${ }^{31}$ In the present study, we synthesize PTMC with different number of arms terminated by hydroxyl group or carboxylic group and study the degradability of such end-group-functionalized PTMCs preliminarily.

\section{EXPERIMENTAL}

1,3-Trimethylene carbonate (TMC) was synthesized according to the reported method ${ }^{32}$ All other regents were treated just before use.

\section{Synthesis of OH-Terminated PTMC (OH-PTMC)}

The ring-opening polymerizations (ROP) of TMC initiated by alcohols are illustrated in Scheme 1. These polymerization reactions were carried out in the melt bulk. All reaction reagents were used just after treated. A known amount of TMC was charged into a previously flamed and nitrogen-purged glass polymerization tube, containing a Teflon-coated magnetic stirring bar. Then an exhausting-refilling process was repeated three times with a $15 \mathrm{~s}$ nitrogen sweeping every $10 \mathrm{~min}$ exhausting at $60^{\circ} \mathrm{C}$. After the tube was cooled at room temperature, alcohol (ethanol, 1,4-butanediol, glycerol, or pentaerythritol) and TFA were added through a dried syringe under $\mathrm{N}_{2}$ atmosphere. The tube was degassed

${ }^{\dagger}$ To whom correspondence should be addressed (Tel: +86-27-87195671, Fax: +86-27-87194465, E-mail: fqyu@public.wh.hb.cn). 


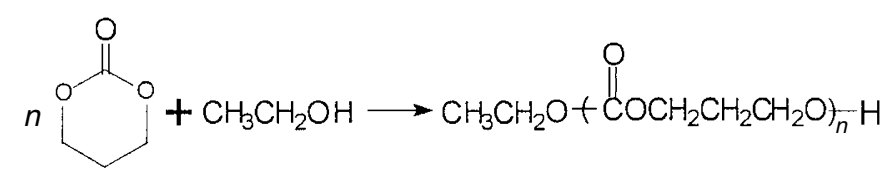

1OH-PTMC

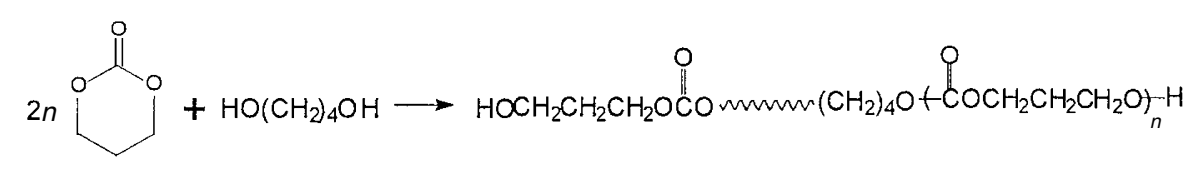

2OH-PTMC<smiles>O=C1CCC[C+]([Se])O1</smiles>

3OH-PTMC

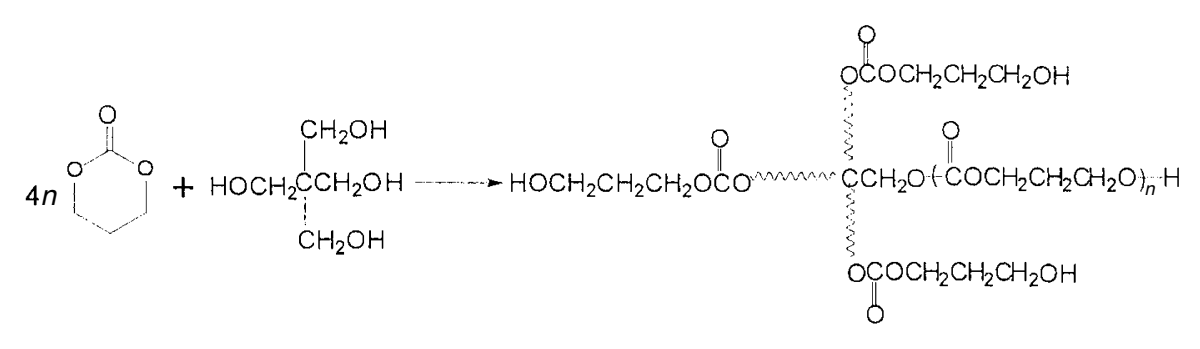

4OH-PTMC

Scheme 1. Synthesis of multiarm OH-terminated PTMCs.

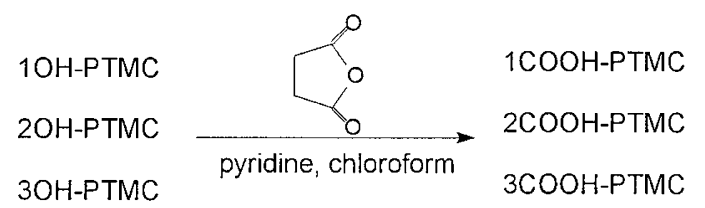

Scheme 2. Synthesis of multiarm COOH-terminated PTMCs.

again and sealed under vacuum within $60 \mathrm{~s}$ and immersed in a thermostated oil bath at $120^{\circ} \mathrm{C}$ for $48 \mathrm{~h}$ with stirring. After the reaction, the tube was broken and the product was dissolved in chloroform, followed by microfiltering through a $0.45 \mu \mathrm{m}$ pore membranes filter. The polymer was precipitated by the polymer solution being poured into an excess of cold diethyl ether, filtered, and dried under vacuum until constant weight.

\section{Synthesis of $\mathrm{COOH}$-Terminated PTMC (COOH- PTMC)}

OH-PTMC was dissolved in chloroform. Succinic anhydride and pyridine were added and the reaction mixture was kept at $60^{\circ} \mathrm{C}$ with stirring for $48 \mathrm{~h}$ (Scheme 2). The solution was cooled, filtered, and concentrated to dryness under vacuum. The crude product was dissolved in acidic water and extracted with chloroform, dried with anhydrous $\mathrm{Na}_{2} \mathrm{SO}_{4}$, and then the solvents were removed under vacuum.

\section{Measurements}

Molecular weights $\left(\bar{M}_{\mathrm{n}}\right.$ and $\left.\bar{M}_{\mathrm{w}}\right)$ and the distributions $\left(\bar{M}_{\mathrm{w}} / \bar{M}_{\mathrm{n}}\right)$ were determined by gel permeation chromatography (GPC) on a Waters 2690D unit 
Table I. The synthetic results of end-group functionalized PTMCs

\begin{tabular}{lccccc}
\hline Run & $\begin{array}{c}{[M] /[I]} \\
(\mathrm{mol} / \mathrm{mol})\end{array}$ & $\begin{array}{c}\text { TMC } \\
\text { conversion } \\
(\%)\end{array}$ & $\bar{M}_{\mathrm{n}, \mathrm{GPC}}$ & $\bar{M}_{\mathrm{n}, \mathrm{NMR}}$ & $\bar{M}_{\mathrm{w}} / \bar{M}_{\mathrm{n}}$ \\
\hline $1 \mathrm{OH}$ & 50 & 92.9 & 6003 & 6125 & 1.82 \\
$2 \mathrm{OH}$ & 56 & 97.1 & 6757 & 6501 & 1.89 \\
$3 \mathrm{OH}$ & 57 & 98.1 & 6248 & 5936 & 1.88 \\
$4 \mathrm{OH}$ & 64 & 80.1 & 6111 & 5459 & 2.09 \\
$1 \mathrm{COOH}$ & - & - & 5865 & 6254 & 1.99 \\
$2 \mathrm{COOH}$ & - & - & 6514 & 6863 & 2.08 \\
$3 \mathrm{COOH}$ & - & - & 6374 & 6334 & 2.07 \\
$4 \mathrm{COOH}$ & - & - & - & - & - \\
\hline
\end{tabular}

equipped with Shodex K802.5 \& K805 with Shodex $\mathrm{K}-\mathrm{G}$ guard column, using chloroform as the eluent at a flow rate of $1.0 \mathrm{~mL} \mathrm{~min}^{-1}$ at $30^{\circ} \mathrm{C}$. Calibration was carried out with polystyrene standards. Proton nuclear magnetic resonance $\left({ }^{1} \mathrm{H}\right.$ NMR) spectra were recorded on NMR spectrometer Mercury-300BB "mercury 300 " in chloroform- $d\left(\mathrm{CDCl}_{3}\right)$ at ambient temperature. Tetramethylsilane (TMS) signal is taken as the zero chemical shift.

\section{In Vitro Degradation}

A round disk of sample was prepared by compression molding $(10 \mathrm{~mm}$ in diameter and $2 \mathrm{~mm}$ in thickness). The in vitro degradation was measured by immersion of polymer disks in phosphate-buffered saline (PBS, pH 7.4) at $37^{\circ} \mathrm{C}$. Each $24 \mathrm{~h}$, the samples were transferred into fresh buffer solution. Samples were recovered at various intervals of time, water washed, and vacuum dried, while weight loss was determined gravimetrically.

\section{RESULTS AND DISCUSSION}

\section{Synthesis of OH-Terminated PTMC (OH-PTMC)}

Polycarbonate degrades slowly although it has many advantages as biomaterials. Incorporation of end group may be a route to enhance its degradation rate in terms of the fact that end-group functionalized polylactide degraded faster.

We first synthesized OH-terminated PTMCs by ROP of TMC initiated by various kinds of alcohols. All polymerizations were conducted in melt bulk with vigorous stirring. The results of polymerization are complied in Table I. Under these conditions, high conversions of TMC were achieved after the predetermined polymerization time.

The content of end-group is higher for the multiarmstructure polymers of the same molecular weight. Ethanol, 1,4-butanediol, glycerol, and pentaerythritol were used as a respective initiator for the synthesis of
OH-terminated poly(trimethylene carbonate) with different arms (Scheme 1). Figures 1, 2, and 3 show the ${ }^{1} \mathrm{H}$ NMR of $1 \mathrm{OH}-\mathrm{PTMC}, 2 \mathrm{OH}-\mathrm{PTMC}$, and $3 \mathrm{OH}-$ PTMC, respectively, with the peak assignments of these products. The peaks of the fragments of alcohols as initiators were observed in NMR spectra. The existence of these fragments in the polymers and the peaks of the proton of $\mathrm{CH}_{2}$ attached to $\mathrm{OH}$ group at the chain end at $3.73 \mathrm{ppm}$ testified that alcohol was the real initiator (Figures 1 and 2). The $\mathrm{CH}_{2}$ (a) and $\mathrm{CH}$ (b) proton resonance from glyceryl group occurred at $4.24 \mathrm{ppm}$ in Figure 3 , overlapped with the $-\mathrm{COOCH}_{2}$ proton (c). The proton (f) of $\mathrm{CH}_{2}$ attached to $\mathrm{OH}$ group at the chain end was observed at $3.73 \mathrm{ppm}$. If the peak (f) was attributed to $\mathrm{CH}_{2}\left(\mathrm{G}-\mathrm{CH}_{2}-\mathrm{OH}\right)$ and $\mathrm{CH}(\mathrm{G}-\mathrm{CH}-\mathrm{OH})$ proton attached to the $\mathrm{OH}$ groups which might not participated in the ROP, occurring at $3.73 \mathrm{ppm}$ also, the appearance of peak (e) at 1.90-1.93 ppm similarly demonstrated the ring-opening polymerization shown in Scheme 1. The following equation was suggested for the determination of the average degree of polymerization $(D P)$ of each arm:

$$
D P=\frac{\chi}{\frac{1}{2}(y+z)}+1
$$

where $x, y$, and $z$ are equal to the integration intensities of peaks d, f, and e, respectively. For the sample of run $3 \mathrm{OH}$ in Table $\mathrm{I}$, the calculated average degree of polymerization was 19.4 . This value is very near to the theoretical average degree of polymerization for each $\mathrm{OH}$ group because the feed molar ratio of TMC over glycerol was 57 . The result implied that all the three $\mathrm{OH}$ groups of glycerol initiated the ROP of TMC and the obtained polymer has three arms, each arm terminated by $\mathrm{OH}$ group. Other results, including molecular weights, are listed in Table I.

When pentaerythritol was used as the initiator for the synthesis of four-armed structure, a gel was observed. Part of the product did not solve in chloroform and the conversion of TMC was relatively lower. So the structure and properties of the expected four-armed structure were not successfully studied.

\section{Synthesis of COOH-Terminated PTMC (COOH- PTMC)}

If introducing $\mathrm{COOH}$ end group into polycarbonate, the end group of $\mathrm{COOH}$ may catalyze the degradation by virtue of the hydrolytic degradation mechanism of polycarbonate catalyzed by both acid and base. $\mathrm{COOH}$-terminated PTMC was synthesized through the ring-opening reaction of the OH-PTMC end group with succinic anhydride (Scheme 2). When pyridine and chloroform were used as the catalyst and sol- 


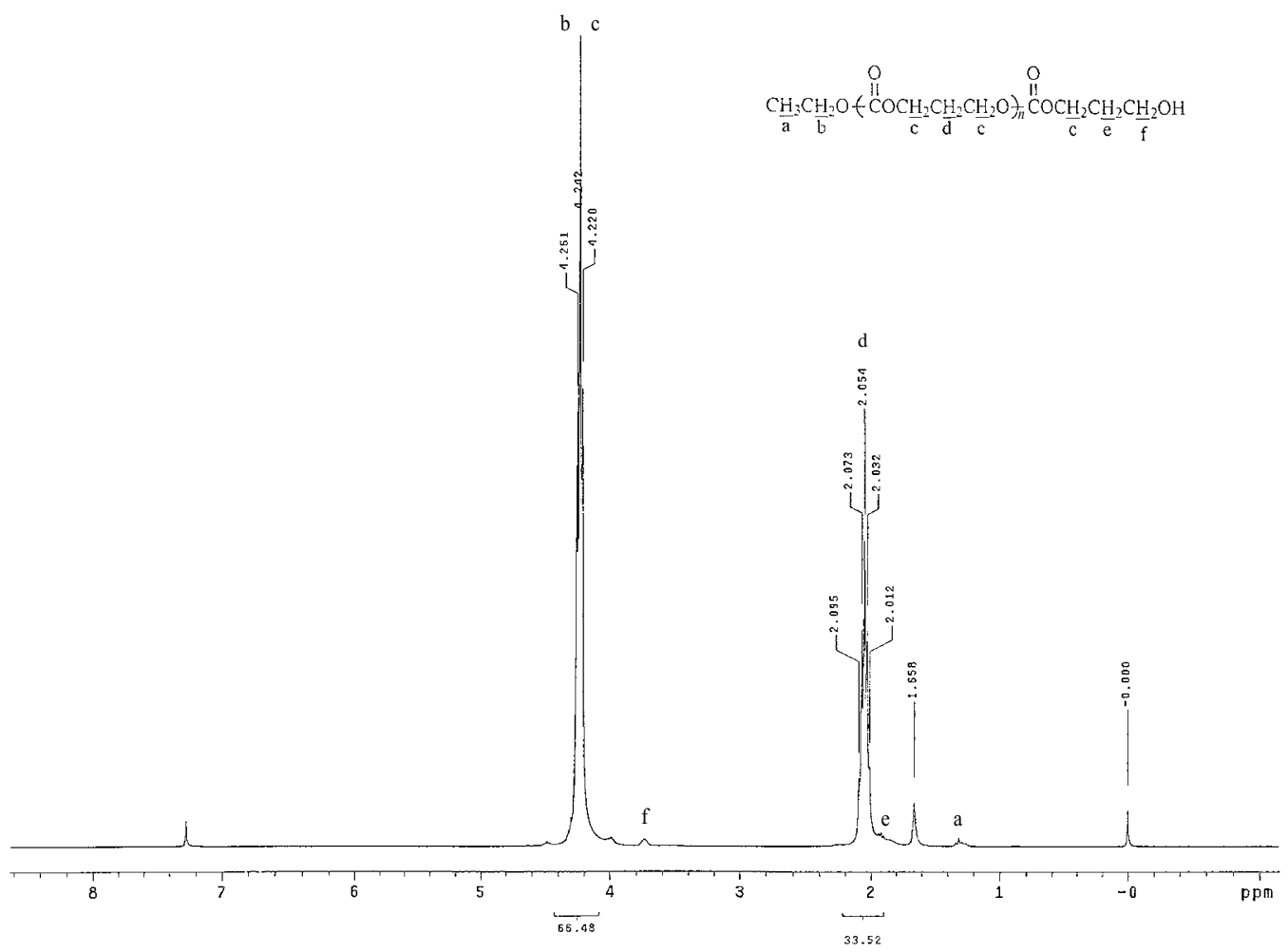

Figure 1. ${ }^{1} \mathrm{H}$ NMR spectrum of the product of $1 \mathrm{OH}-\mathrm{PTMC}$.

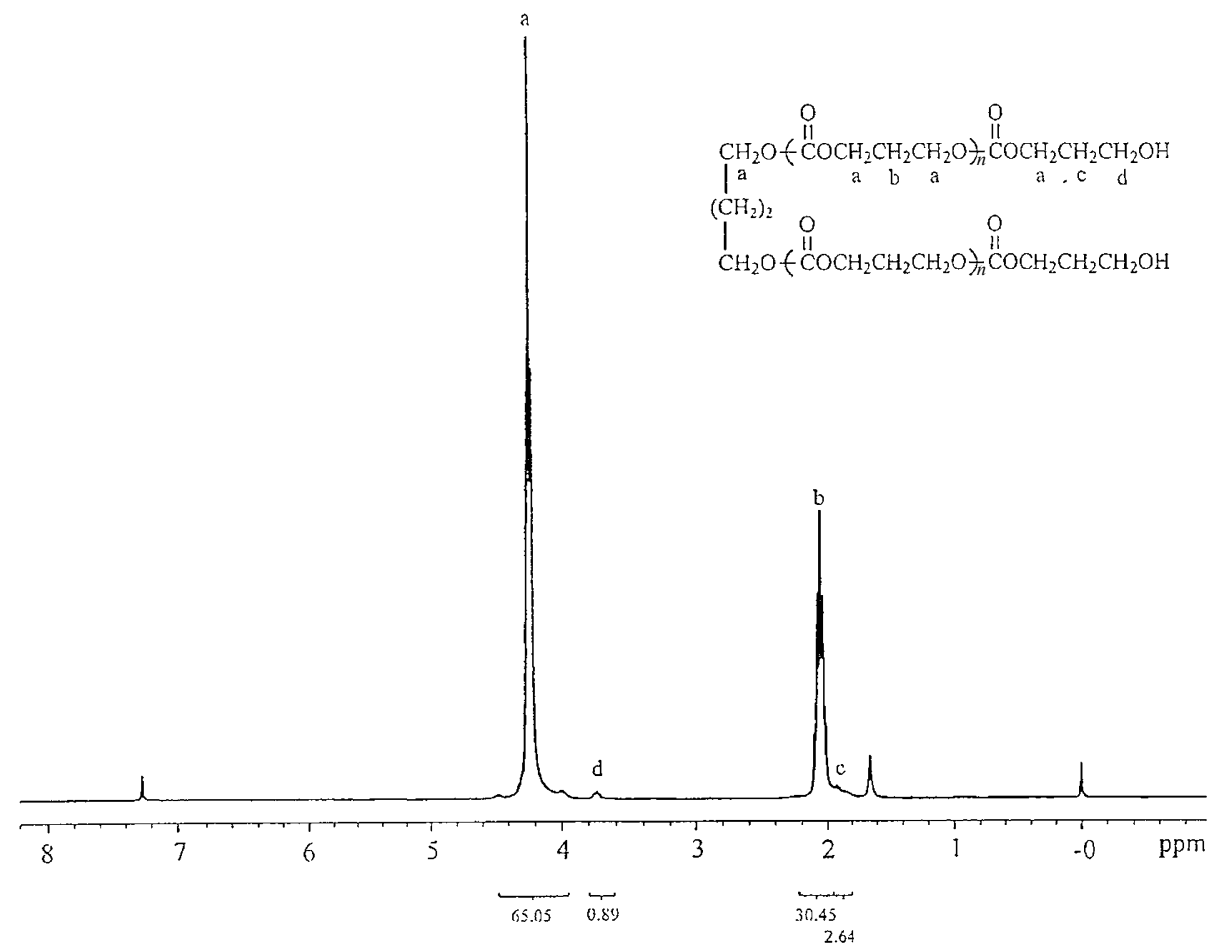

Figure 2. ${ }^{1} \mathrm{H}$ NMR spectrum of the product of $2 \mathrm{OH}-\mathrm{PTMC}$.

vent, respectively, the ring-opening reaction proceeded efficiently. Figure 4 shows the ${ }^{1} \mathrm{H}$ NMR spectrum of $\mathrm{COOH}$-terminated three-arm poly(trimethylene carbonate). The methylene proton at $3.73 \mathrm{ppm}$ (Figure 3, f) attached to $\mathrm{OH}$ group at the chain terminus disappeared, and the methylene proton formed by the ringopening reaction of succinic anhydride was observed at
$2.65 \mathrm{ppm}$. These observations confirmed the expected reaction shown in the Scheme 2 and that all the $\mathrm{OH}$ termini were consumed to form $\mathrm{COOH}$ termini.

\section{In Vitro Degradation}

The hydrolysis degradation of such end-functionalized PTMCs was investigated. The factors contribut- 


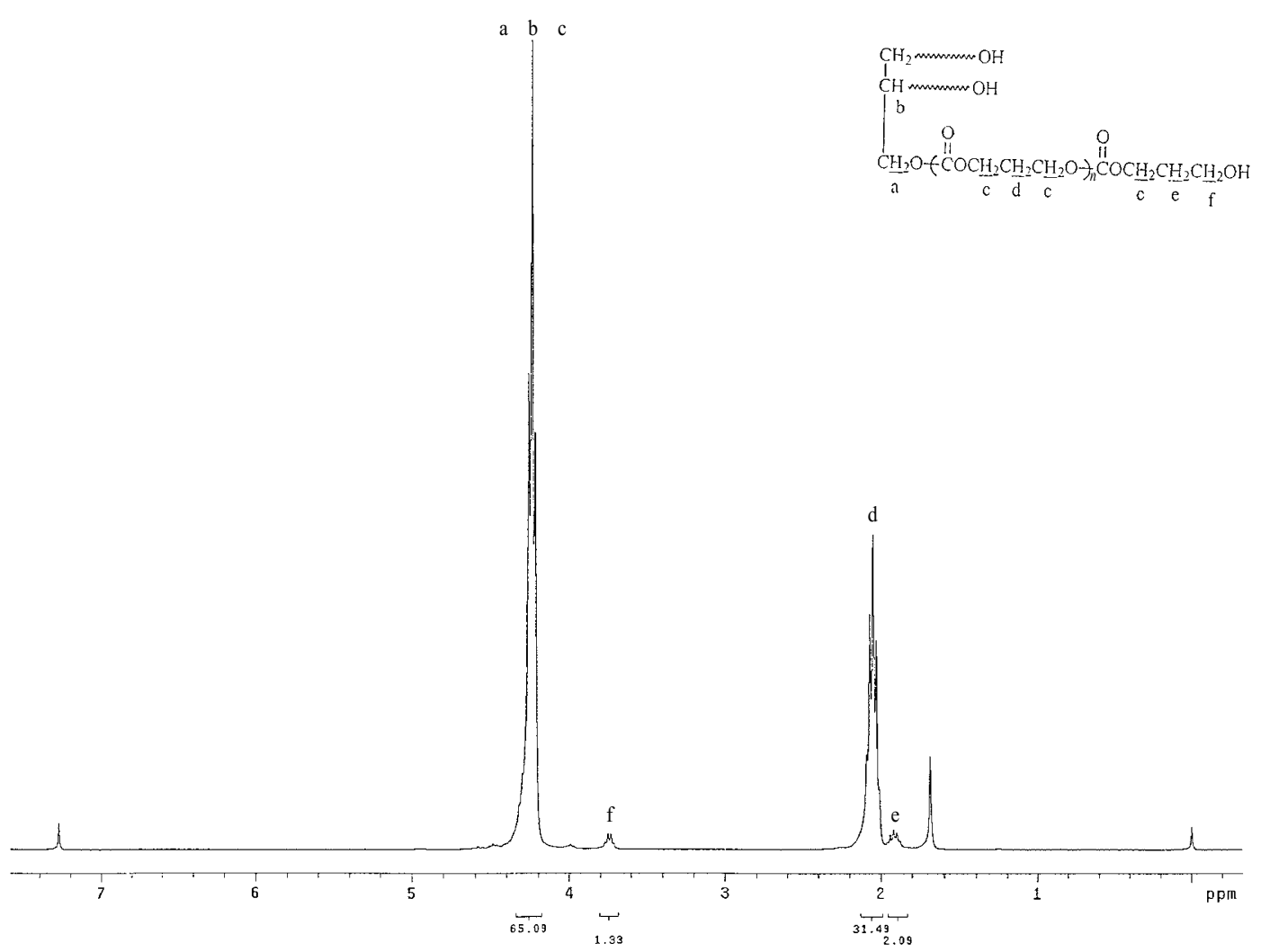

Figure 3. ${ }^{1} \mathrm{H}$ NMR spectrum of the product of $3 \mathrm{OH}-\mathrm{PTMC}$.

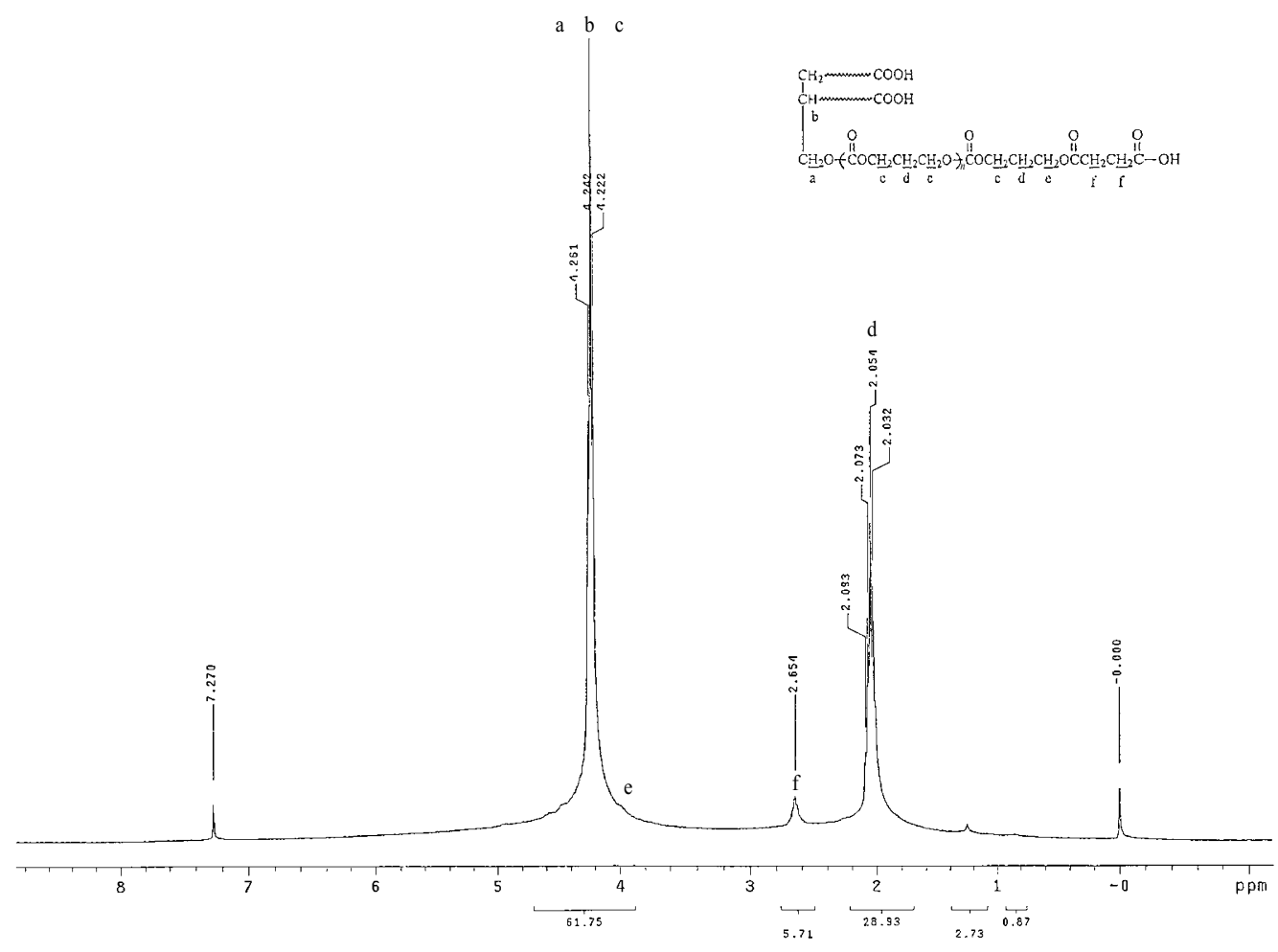

Figure 4. ${ }^{1} \mathrm{H}$ NMR spectrum of $\mathrm{COOH}$-terminated three-arm PTMC.

ing to accelerated degradation are the nature and the number of terminal groups.

Figures 5 and 6 illustrate the weight loss behaviors, which occurred by immersion of the samples in a $\mathrm{pH} 7.4$ buffer solution at $37^{\circ} \mathrm{C}$. As can be seen, these characteristics were strongly dependent on the endgroup type and number. The $\mathrm{OH}$-end-group seemed no special effect on the increase of degradation rate of PTMC during the observation period no matter what the concentration of terminal groups was. However, it ap- 


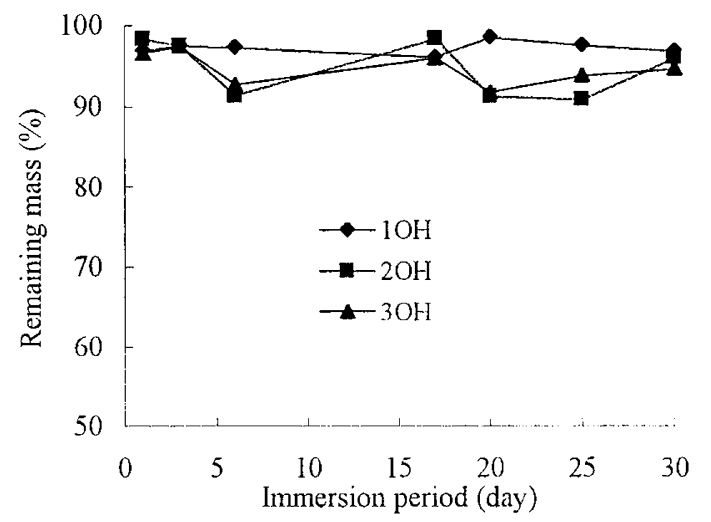

Figure 5. Mass remaining after the hydrolytic degradation of OH-terminated multiarm PTMCs.

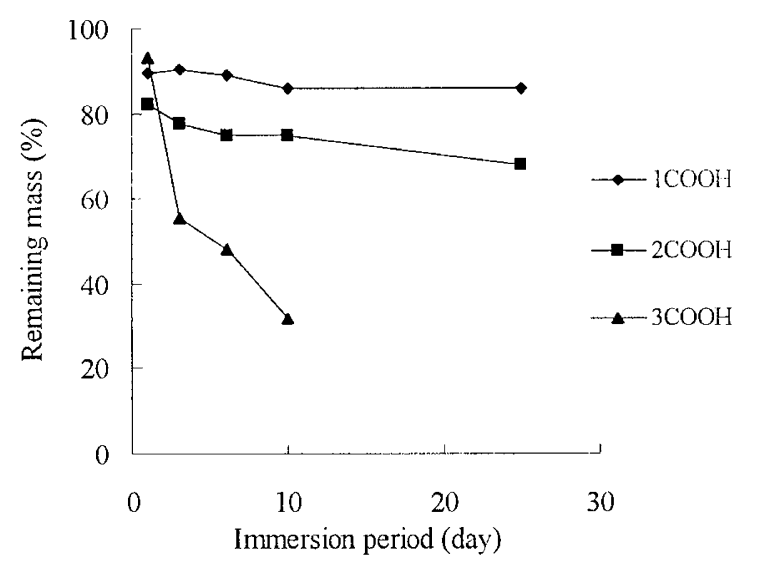

Figure 6. Mass remaining after the hydrolytic degradation of $\mathrm{COOH}$-terminated multiarm PTMCs.

peared that $\mathrm{COOH}-\mathrm{PTMCs}$ were hydrolyzed faster than the OH-PTMCs. It is well known that acid plays a role as a degradation catalyst, which accelerates the hydrolysis of ester bonds in the polymer backbone. Generally, hydrolytic degradation increases as acidity increases. The multiarm structure polymers have higher concentration of $\mathrm{COOH}$ end group and higher acidity than the linear polymers of the same molecular weight, thus they should degrade faster. This was in line with our observation that the one-, two-, and three-arm structures terminated by $\mathrm{COOH}$ degraded increasingly in order.

In summary, although poly(trimethylene carbonate) degrades slowly, the introduction of $\mathrm{COOH}$ end-group accelerates its degradation.

\section{REFERENCES}

1. L. Lu, C. A. Garcia, and A. G. Mikos, J. Biomed. Mater. Res., 46, 236 (1999).

2. Y. Zhang, S. Zale, L. Sawyer, and H. Bernstein, J. Biomed. Mater. Res., 34, 531 (1997).

3. S. Li, S. Girod-Holland, and M. Vert, J. Controlled Release, 40, 41 (1996).
4. K. Juni, J. Ogata, N. Matsui, M. Kubota, and M. Nakano, Chem. Pharm. Bull., 33, 1734 (1985).

5. K. H. Lee, C. Y. Won, C. C. Chu, and I. Gitsov, J. Polym. Sci., Part A: Polym. Chem., 37, 3558 (1999).

6. D. R. Witzke, R. Narayan, and J. J. Kolstad, Macromolecules, 30, 7075 (1997).

7. H. R. Kricheldorf, I. Kreiser-Saunders, and C. Boettcher, Polymer, 36, 1253 (1995).

8. G. Schwach, J. Coudane, R. Engel, and M. Vert, J. Polym. Sci., Part A: Polym. Chem., 35, 3431 (1997).

9. M. Vert, G. Schwach, R. Engel, and J. Coudane, J. Controlled Release, 53, 85 (1998).

10. A. C. Albertsson and M. Eklund, J. Appl. Polym. Sci., 57, 87 (1995).

11. C. M. Dong, K. Y. Qiu, Z. W. Gu, and X. D. Feng, Polymer, 42, 6891 (2001).

12. I. Arvanitoyannis, A. Nakayama, N. Kawasaki, and N. Yamamoto, Polymer, 36, 2271 (1995).

13. S. H. Kim, Y. K. Han, Y. H. Kim, and S. I. Hong, Makromol. Chem., 193, 1623 (1992).

14. H. R. Kricheldorf and J. Meier-Haack, Makromol. Chem., 194, 715 (1993).

15. S. G. Wang and B. Qiu, Polym. Adv. Technol., 4, 363 (1993).

16. H. Wang, J. H. Dong, K. Y. Qiu, and Z. W. Gu, Gaofenzi Xuebao, 3, 319 (1997).

17. A. C. Albertsson and M. Eklund, J. Polym. Sci., Part A: Polym. Chem., 34, 1395 (1996).

18. B. S. Kim, J. S. Hrkach, and R. Langer, J. Polym. Sci., Part A: Polym. Chem., 38, 1277 (2000).

19. M. Ohrlander, T. Lindberg, A. Wirsen, and A. C. Albertsson, J. Polym. Sci., Part A: Polym. Chem., 37, 1651 (1999).

20. M. Ohrlander, R. Palmgren, A. Wirsen, and A. C. Albertsson, J. Polym. Sci., Part A: Polym. Chem., 37, 1659 (1999).

21. S. H. Lee, S. H. Kim, Y. K. Han, and Y. H. Kim, J. Polym. Sci., Part A: Polym. Chem., 39, 973 (2001).

22. M. A. Tracy, K. L. Ward, L. Firouzabadian, Y. Wang, N. Dong, R. Qian, and Y. Zhang, Biomaterials, 20, 1057 (1999).

23. S. J. de Jong, E. R. Arias, D. T. S. Rijkers, C. F. van Nostrum, J. J. Kettenes-van den Bosch, and W. E. Hennink, Polymer, 42, 2795 (2001).

24. D. Teomim and A. J. Domb, J. Polym. Sci., Part A: Polym. Chem., 37, 3337 (1999).

25. K. J. Zhu, R. W. Hendren, K. Jensen, and C. G. Pitt, Macromolecules, 24, 1736 (1991).

26. J. Cai, K. J. Zhu, and S. L. Yang, Polymer, 39, 4409 (1998).

27. S. Pulapura and J. Kohn, Biopolymers, 32, 411 (1992).

28. K. A. Hooper, J. D. Cox, and J. Kohn, J. Appl. Polym. Sci., 63, 1499 (1997).

29. N. Suarez, E. Laredo, A. Bello, and J. Kohn, J. Appl. Polym. Sci., 63, 1457 (1997).

30. Y. Shen, X. Chen, and R. A. Gross, Macromolecules, 32, 2799 (1999).

31. J. Matsuo, S. Nakano, F. Sanda, and T. Endo, J. Polym. Sci., Part A: Polym. Chem., 36, 2463 (1998).

32. T. Ariga, T. Takata, and T. Endo, J. Polym. Sci., Part A: Polym. Chem., 31, 581 (1993). 